\title{
X Chromosome Inactivation Patterns Correlate with Fetal-Placental Anatomy in Monozygotic Twin Pairs: Implications for Immune Relatedness and Concordance for Autoimmunity
}

\author{
Velia Trejo, ${ }^{*}$ Catherine Derom, ${ }^{\dagger}$ Robert Vlietinck, ${ }^{\dagger}$ \\ William Ollier, $\neq$ Alan Silman,,$^{\ddagger}$ George Ebers, $\$$ Robert Derom, ${ }^{\dagger}$ \\ and Peter K. Gregersen* \\ *Departments of Medicine, North Shore University Hospital and \\ Cornell University Medical College, Manhasset, New York, U.S.A. \\ ${ }^{\dagger}$ Centrum voor Menselijke Erfelijkheid, Katholieke Universiteit, \\ Leuven, Belgium \\ ${ }^{\ddagger}$ ARC Epidemiology Research Unit, University of Manchester, \\ United Kingdom \\ ${ }^{\S}$ Department of Neurology, University of Western Ontario, London, \\ Ontario, Canada
}

\begin{abstract}
Background: Monozygotic (MZ) twinning is a poorly understood phenomenon that may result in subtle biologic differences between twins, despite their identical inheritance. These differences may in part account for discordant expression of disease in $\mathrm{MZ}$ twin pairs. Due to their stochastic nature, differences in $\mathrm{X}$ chromosome inactivation patterns are one source of such variation in female $M Z$ twins.

Materials and Methods: We investigated X chromosome inactivation patterns in the blood of $41 \mathrm{MZ}$ twin pairs based on methylation of the androgen receptor gene using a Hpa II-PCR assay. Twenty-six female MZ twin pairs with autoimmune disease (rheumatoid arthritis or multiple sclerosis) were studied. In addition, we studied 15 newborn female MZ twin pairs who were characterized at birth with respect to the anatomy of chorionic membranes (dichorionic versus monochorionic).
\end{abstract}

Results: We found a strong correlation between dichorionic fetal anatomy and differences in X chromosome inactivation patterns between members of an $\mathrm{MZ}$ twin pair. In contrast, all monochorionic twin pairs had closely correlated patterns of $\mathrm{X}$ chromosome inactivation. $X$ chromosome inactivation patterns did not distinguish between $\mathrm{MZ}$ twin pairs who were concordant or discordant for autoimmune disease.

Conclusions: The highly similar patterns of X chromosome inactivation among monochorionic twin pairs may result from their shared placental blood supply during intrauterine life. Alternatively, these patterns may indicate that $\mathrm{X}$ chromosome inactivation occurs before the twinning event in this anatomic subgroup of $\mathrm{MZ}$ twins. The data further suggest that these factors do not make a major contribution to the high discordance rates for autoimmune disease in $\mathrm{MZ}$ twin pairs.

\section{INTRODUCTION}

The phenomenon of monozygotic twinning is a poorly understood biological event that exhibits heterogeneity with respect to the timing of twin-

Address correspondence and reprint requests to: Dr. Peter K. Gregersen, Department of Medicine, North Shore University Hospital, 350 Community Drive, Manhasset, New York 11030, U.S.A. ning and the anatomic features of the fetal-placental relationship. $\mathrm{MZ}$ twins are commonly divided into two major types: dichorionic and monochorionic (1). Dichorionic twins appear to result from an early twinning event (before 4 days postfertilization) and exhibit two separate placentas which even when physically juxtaposed are divided by the chorionic membranes. In contrast, monochorionic twins appear to re- 
sult from later twinning events (after 4 days postfertilization), in which case the two embryos are connected to a common placenta. Most monochorionic twins develop within separate amniotic sacs, but they nevertheless share a common placental blood supply (1). These different anatomic relationships might be predicted to influence the degree of similarity between twins, at least with respect to circulating hematopoietic elements, and may have particular relevance to the circulating immune system, inasmuch as genetic rearrangement events occur during fetal development in the $\mathrm{T}$ cell and immunoglobulin receptor loci (2). Most twin studies have failed to take these anatomic differences into account, in large part because retrospective determination of placental anatomy is usually not possible.

In this study we have investigated $X$ chromosome inactivation patterns in the peripheral blood of a group of normal MZ twin pairs in whom fetal-placental anatomy was defined at birth. The rationale for doing this relates to the stochastic nature of $\mathrm{X}$ chromosome inactivation in females. In order to avoid a functionally diploid state and thereby achieve a gene dosage comparable to males, each somatic cell of the developing female embryo inactivates either the maternally or paternally derived $\mathrm{X}$ chromosome (3). This event occurs early in development, in perhaps as few as 10 cells (4), and is largely random with respect to which $\mathrm{X}$ chromosome is inactivated. $\mathrm{X}$ chromosome inactivation results in the transcriptional silencing of many (though not all) genes on the $X$ chromosome and is accompanied by methylation of the DNA in many of these silenced genes (3). The different methylation status of genes on the inactive versus active $\mathrm{X}$ chromosome allows for the distinction of these chromosomes using methylation-sensitive restriction enzymes (5).

A wide variation in the patterns of $\mathrm{X}$ chromosome utilization can be observed between individual females (4) and indeed in different members of monozygotic twin pairs. This can occasionally lead to biological differences between MZ twins, as has been described for a number of $\mathrm{X}$ linked diseases and phenotypes (6-9). We therefore reasoned that $X$ chromosome inactivation patterns in peripheral blood should be more similar in twins with a shared placental blood supply (monochorionic twins), compared with twins in whom no connection in blood supply is present (dichorionic twins). The data reported here have established this relationship for the first time.
Discordant expression of autoimmune disease is common in MZ twins. When one MZ twin is affected with diseases such as juvenile diabetes, multiple sclerosis, and systemic lupus, the co-twin remains unaffected in approximately two-thirds of cases (10-12). Several recent studies of rheumatoid arthritis have indicated that discordance for this disease in $\mathrm{MZ}$ twins is even more common, with concordance rates as low as $15 \%(13)$. These data have generally been interpreted as reflecting a large environmental component in the pathogenesis of these illnesses. However, the influence of placental anatomy or other fetal developmental events on disease concordance has not been previously explored. We therefore extended our analysis of $\mathrm{X}$ chromosome inactivation patterns to a population of $\mathrm{MZ}$ twins with autoimmune disease in order to address this question.

\section{MATERIALS AND METHODS}

\section{Study Subjects}

Fifteen pairs of normal newborn $\mathrm{MZ}$ female twins were collected at the Centrum voor Menselijke Erfelijkheid, Katholieke Universiteit, Leuven, Belgium. At the time of birth, cord blood samples of each individual were collected. A detailed anatomic analysis of the placenta and fetal membranes was performed in order to classify twin pairs as either monochorionic or dichorionic. In addition, blood samples from 16 pairs of MZ female twins with rheumatoid arthritis (7 concordant and 9 discordant) were collected at the ARC Epidemiology Research Unit, University of Manchester, Great Britain. Ten MZ twins with multiple sclerosis were collected at the Department of Clinical Neurological Sciences, University Hospital, London, Ontario. Three of these twins were discordant for disease, both clinically and by MRI scanning. The remaining seven twins with MS were concordant, determined either clinically (four twins) or solely by virtue of a positive MRI (three twins). The zygosity of the twins was established by analysis with minisatellite probes (14).

\section{HpaII/PCR Assay for X Chromosome Inactivation}

$\mathrm{X}$ chromosome inactivation patterns were determined using an HpaII/PCR assay for the X-linked androgen receptor (AR) gene (5). The AR gene is 


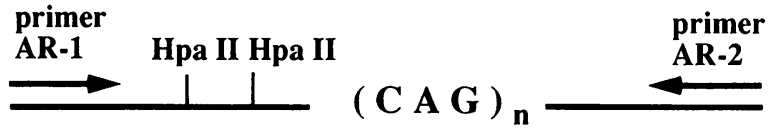

$\mathrm{n}=\mathbf{1 7}-\mathbf{2 6}$ in normal individuals

FIG. 1. Schematic map of a portion of the first exon of the androgen receptor gene

The polymorphic CAG triplet repeat is flanked by HpaII sites and the locations of the primers ARI and AR2 used for the PCR assay are indicated.

methylated on the inactive $\mathrm{X}$ and undermethylated on the active $X$ chromosome in normal females. Furthermore, as shown in Fig. 1, a highly polymorphic triplet repeat within the AR gene allows for the discrimination of each $\mathrm{X}$ chromosome in most female subjects (5).

An outline of the method used for this study is shown in Fig. 2. Briefly, 100-200 ng of genomic DNA was digested with the methylation-sensitive restriction enzyme Hpall, according to the recommendations of the manufacturer (GIBCO, BRL, Gaithersberg, MD, U.S.A.). A mock sample was prepared in parallel, as a control, without the addition of HpaII. After overnight digestion, samples were boiled for $30 \mathrm{~min}$ to inactivate the HpaII enzyme. PCR amplification of the AR gene was performed with 10-20 ng of DNA (either HpaII or mock digested). Primers ARI (5' -TCCAGAATCTGTTCCAGAGCGTGC3') and AR2 (5'-GCTGTGAAGGTTGCTGTTCCT CAT- $3^{\prime}$ ) were chosen to flank the triplet repeat (CAG) and the HpaII sites in the first exon of the AR gene (Fig. 1). The AR2 primer was end la- beled with ${ }^{32} \mathrm{P}$ using $\mathrm{T}_{4}$ polynucleotide kinase (Promega, Madison, WI, U.S.A.). A standard PCR amplification reaction with 3 pmol of each primer was performed with $10 \%$ glycerol in a 50 $\mu l$ volume. The PCR conditions were as follows: denaturation at $94^{\circ} \mathrm{C}$ for $30 \mathrm{sec}$, annealing at $60^{\circ} \mathrm{C}$ for $30 \mathrm{sec}$, and extension at $72^{\circ} \mathrm{C}$ for $30 \mathrm{sec}$. After 30 cycles, PCR products were loaded on either a $6 \%$ or $8 \%$ polyacrylamide denaturing (8 $\mathrm{M}$ urea) gel in order to obtain an optimal separation of the two alleles. The gel was exposed overnight on Hyper film-MP (Amersham, CEA $A B$, Sweden), with intensifying screens. Quantitation of the PCR bands was performed using a phosphorimager (Molecular Dynamics Model CPD-1430, Sunnyvale, CA, U.S.A.). All samples were run in duplicate.

\section{Calculation of $\mathbf{X}$ Chromosome Inactivation}

Measurements obtained in counts per minute (cpm) from the phosphorimager were analyzed as follows. The relative intensity of the larger AR allele (upper band) with respect to the smaller AR allele (lower band) was calculated and expressed as a ratio, $R=\mathrm{cpm}$ in upper band/cpm in lower band. The ratios in the mock digested $\left(R_{\mathrm{M}}\right)$ and HpaII-digested $\left(R_{\mathrm{H}}\right)$ samples were calculated separately. For each individual, a normalized ratio $R_{\mathrm{N}}=\left(R_{\mathrm{H}}\right) /\left(R_{\mathrm{M}}\right)$ was calculated to correct for occasional minor variations in the efficiency of amplification of the two AR alleles. This normalized ratio was used to determine the percent inactivation of the $\mathrm{X}$ chromosome bearing the larger (upper) $\mathrm{AR}$ allele: \% inactivation $=\left[R_{\mathrm{N}} /\right.$ $\left.\left(R_{\mathrm{N}}+1\right)\right] \times 100$. We have arbitrarily chosen to

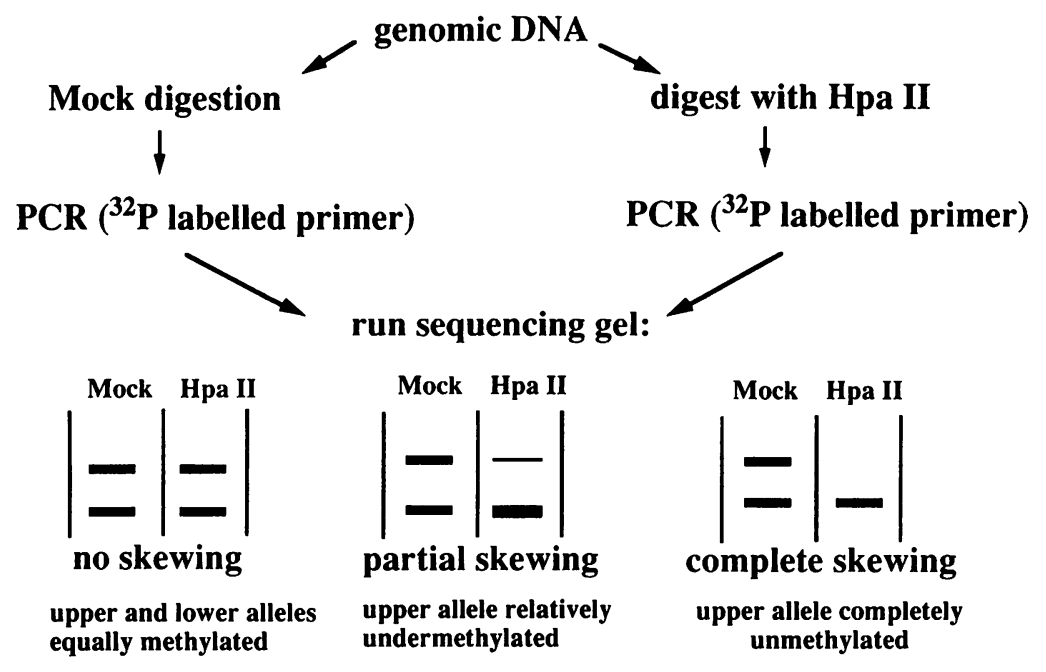

FIG. 2. Flow diagram of the HpaII/PCR assay

After radioactive PCR across the triplet (CAG) repeat of the AR gene, two alleles of different length are observed in mock digested genomic DNA from heterozygous females. When the PCR is performed after the HpaII digestion of the target DNA, the intensity of each band reflects the relative degree of methylation of each AR allele. A schematic illustration of the results obtained for various degrees of inactivation (methylation) of the X chromosome bearing the lower AR allele is shown at the bottom of the figure. 
express our data as percent inactivation of the $\mathrm{X}$ chromosome bearing the upper AR allele, since we do not have information regarding the parental origin of the two AR alleles in our twin pairs.

Standardized difference values were calculated to determine the similarity of the $\mathrm{X}$ chromosome inactivation patterns between the members of each twin pair. Briefly, the duplicate PCR determinations for each individual were used to calculate the mean value $(X)$ of percent $X$ inactivation (upper allele) for each individual, as well as the variance $(S)$. The pooled variance values for each twin pair were determined by the formula:

$$
S_{\mathrm{p}}=\sqrt{\left[\left(S_{1}^{2}+S_{2}^{2} \times 1 /\left(n_{1}+n_{2}-2\right)\right]\right.},
$$

where $S_{1}=\Sigma\left(X_{i}-X\right)^{2}$ and $S_{2}=\Sigma\left(X_{i}-X\right)^{2}$ ( $1=$ individual twin $1 ; 2=$ individual twin 2$)$. Finally, the standardized difference was calculated as standardized difference $(\mathrm{SD})=\left(X_{1}-\right.$ $\left.X_{2}\right) / S_{\mathrm{p}}$.

\section{RESULTS}

We have determined $\mathrm{X}$ chromosome inactivation patterns in $41 \mathrm{MZ}$ twin pairs. As seen in Fig. 3, out of the 82 individuals studied, the majority showed $\mathrm{X}$ chromosome inactivation patterns close to 50:50, although a considerable number of subjects displayed substantial skewing toward utilization of one or the other X chromosome. Indeed, we identified a few individuals who appeared to utilize one $\mathrm{X}$ chromosome almost exclusively (close to $0 \%$ or $100 \%$ methylation of the larger AR allele). These data are generally consistent with data on $\mathrm{X}$ chromosome inactivation patterns in normal females, generated by alternative methods (4). In addition, no particular pattern was found for the group of RA twins (whether discordant or concordant for disease) when compared with the normal MZ twins (data not shown).

We then addressed the degree of intrapair differences in $\mathrm{X}$ inactivation patterns for the various groups of $\mathrm{MZ}$ twin pairs. Representative examples of the different patterns observed are shown in Fig. 4. In twin pair 109 (Fig. 4A), both members of the pair exhibit roughly equivalent utilization of both $\mathrm{X}$ chromosomes. Comparing the bands of the PCR for the mock reaction with the ones for the HpaII digestion the intensity is equivalent in the two samples. Therefore, for both members of this twin pair each $\mathrm{X}$ chromo-

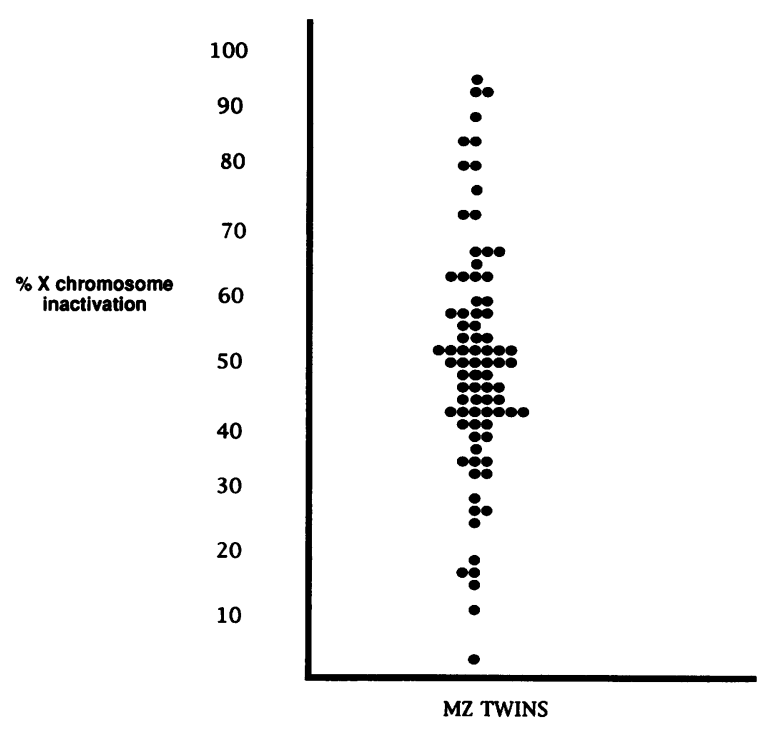

FIG. 3. $X$ chromosome inactivation patterns Percent inactivation of the $\mathrm{X}$ chromosome carrying the larger AR allele (upper band, chosen arbitrarily) for $41 \mathrm{MZ}$ female twins (82 individuals). Dots represent the average of duplicate determinations from each individual.

some is active in roughly $50 \%$ of the cells in peripheral blood. A different pattern is observed in twin pair 186 (Fig. 4B). Twin 186A has preferentially inactivated the $\mathrm{X}$ chromosome carrying the upper allele. After HpaII digestion, the upper band is much more prominent (compare lanes $\mathrm{H}$ with lanes $\mathrm{M}$ ). This band corresponds to the preferentially methylated or "protected allele" present on the inactive $\mathrm{X}$ chromosome. The relatively faint lower band corresponds to the undermethylated or "unprotected" allele from the active $\mathrm{X}$ chromosome. The calculated mean percent inactivation of the upper allele is $78 \%$, indicating that in approximately $78 \%$ of the circulating peripheral blood lymphocytes this $\mathrm{X}$ chromosome is inactive. In contrast, the co-twin $186 \mathrm{~B}$ exhibits a roughly equal $(51 \%)$ pattern of $\mathrm{X}$ chromosome inactivation. Thus, the members of twin pair 186 have distinctly different patterns of $\mathrm{X}$ chromosome inactivation.

A third, much less common, pattern of $\mathrm{X}$ chromosome inactivation is shown in Fig. 4C. As shown for twin pair 490, we have occasionally seen a highly nonrandom pattern of $\mathrm{X}$ chromosome inactivation in both members of a twin pair. Thus, almost all the peripheral blood cells in these twins preferentially utilize only one of the two inherited $\mathrm{X}$ chromosomes. We have observed this similar pattern of extreme skewing in 
A
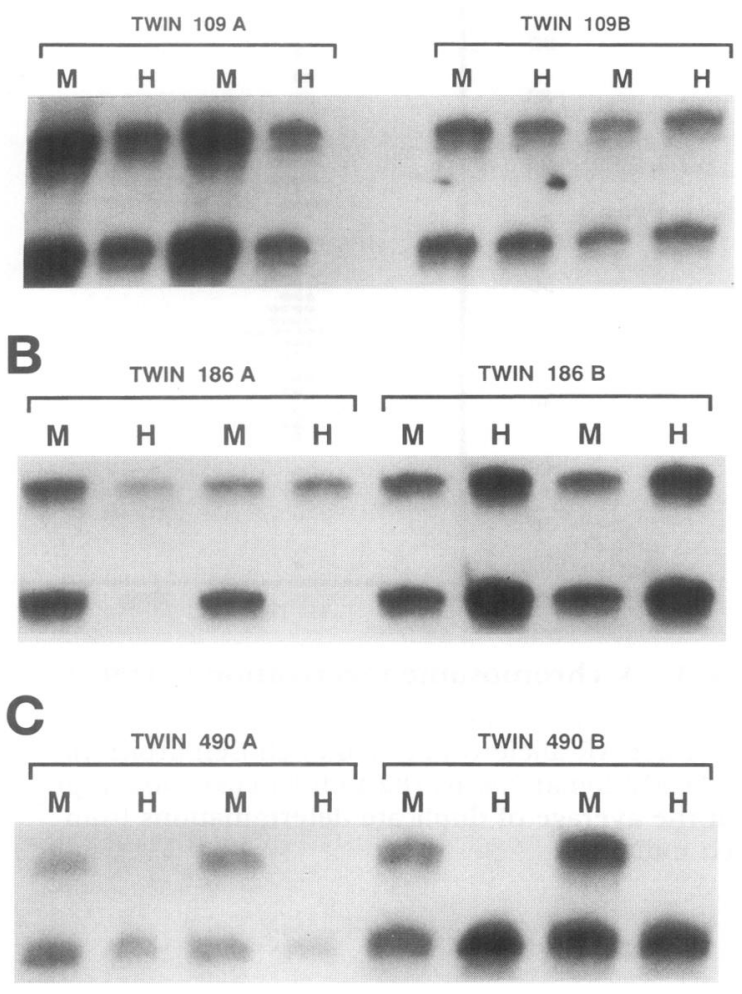

FIG. 4. Comparison of $X$ chromosome inactivation patterns among members of $\mathrm{MZ}$ twins pairs

In (A), twins 109A and 109B show similar patterns of $X$ inactivation around 50:50. In (B), twin 186A exhibits skewing toward inactivation of the $\mathrm{X}$ chromosome bearing the upper $\mathrm{AR}$ allele. Her co-twin 186B does not have preferential skewing toward either $X$ chromosome. In (C), both twins $490 \mathrm{~A}$ and $490 \mathrm{~B}$ are extremely skewed toward inactivation of the $X$ chromosome bearing the smaller (lower band) AR allele. $M=$ mock-digested DNA; $H=$ HpaIIdigested DNA. All assays were performed in duplicate, as shown.

only 2 twin pairs out of the 41 pairs reported in this study.

In order to quantify the degree of intrapair differences in $\mathrm{X}$ chromosome inactivation patterns, we calculated the SD in the mean values for each twin pair, as shown in Fig. 5. For the group of 41 twin pairs, a wide variation in SD values was observed. Some twins show highly similar $X$ inactivation patterns (low SD values), whereas other twin pairs exhibit distinctly different patterns of $X$ chromosome inactivation (high SD values). For example, twin pair 186 (Fig. 4B) has a calculated $\mathrm{SD}=13.9$.
As shown in Fig. 5, a striking correlation was observed between a monochorionic anatomy in twin pairs and the presence of low values for standardized difference. All monochorionic twins exhibited SD values $<4.0$, whereas four out of seven dichorionic twin pairs had SD values $>4.0$ (range $0.5-10.7$ ). This difference was statistically significant $(p=0.026$, Fisher's exact test). As discussed below, we believe the uniformly similar patterns found in monochorionic twins reflects the fact that they share their blood supply during intrauterine life. In contrast, we found no difference in SD values among twin pairs concordant for RA or MS compared with twins discordant for these diseases. In the RA group, we did not observe any trends when age of onset, the presence of erosions, or HLA type were taken into account, although the small number of subjects did not permit a statistically meaningful analysis.

\section{DISCUSSION}

The central finding of this study is that patterns of $\mathrm{X}$ chromosome inactivation in $\mathrm{MZ}$ twins are strongly correlated with the presence or absence of a shared fetal blood supply during intrauterine life. While very little is known concerning the underlying biology of monozygotic twinning, it is probable that the splitting of a developing embryo generally occurs over a time frame ranging from shortly after fertilization to as long as $\mathbf{8}$ days later (1). In about one-third of cases, monozygotic twinning occurs early and results in a dichorionic twin pregnancy (1). In this case, the two embryos and chorionic sacs are entirely separate, without significant connections of fetal blood supply. This has recently been confirmed in a series of 253 dichorionic twin pairs in which dye injection of placental vessels revealed no evidence of macroscopic vascular anastomosis in any twin pair (C. Derom, unpublished data). In the remaining two-thirds of $\mathrm{MZ}$ twins, the twinning event occurs later and results in a monochorionic twin pregnancy in which a common blood supply exists by means of a shared placenta (1). Thus, in the case of monochorionic twins the circulating hematopoietic elements are shared among the twins throughout intrauterine life.

The data presented here demonstrate a correlation between this anatomic feature of monochorionic twins and similar patterns of $\mathrm{X}$ chromosome inactivation in female twin pairs. 


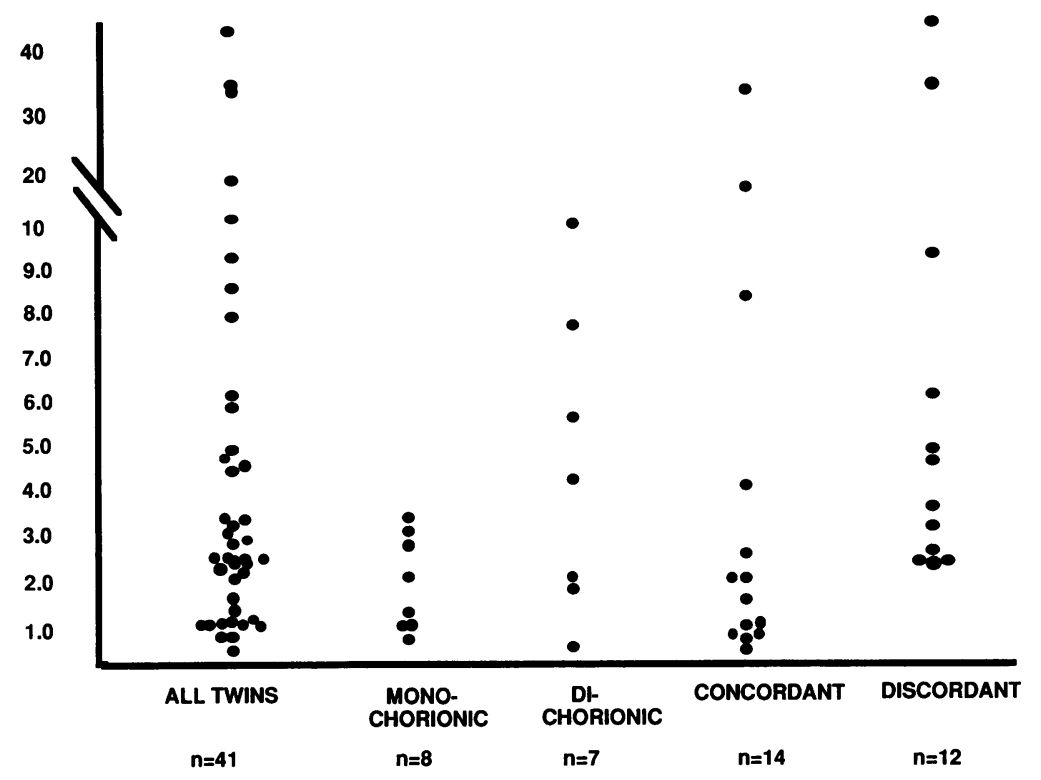

FIG. 5. Comparison of the SD values for $X$ inactivation patterns in various groups of twins

The distribution of SD values for all 41 twin pairs is shown at the left. The monochorionic, dichorionic, concordant $(\mathrm{C})$, and discordant (D) twins are also plotted separately.
Overall, we have confirmed that in any given individual female there may be a wide variation in the degree to which each parental X chromosome is utilized (Fig. 3). However, when members of specific $M Z$ twin pairs are studied, we find that some twins have highly similar patterns of $X$ chromosome utilization (Figs. 4A and 4C), while other twins have strikingly different patterns of $X$ chromosome utilization (Fig. 4B). When the type of fetal-placental anatomy is taken into consideration, it becomes clear that monochorionic twin pairs always exhibit highly similar patterns of $\mathrm{X}$ chromosome inactivation. This is shown in Fig. 5, in which the standardized difference in $X$ inactivation patterns is plotted for the different groups of twins. Note that all monochorionic twins have SD values $>4.0$. This is in contrast to dichorionic twins, in whom SD values $>4.0$ are common (four out of seven twins).

The high frequency of dissimilar patterns of $\mathrm{X}$ chromosome inactivation in dichorionic $\mathrm{MZ}$ twins reflects the underlying stochastic nature and highly variable outcome of this process. Since each member of the twin pair undergoes $X$ inactivation independently, they frequently differ as to which parental $X$ chromosome is preferentially utilized. Occasionally, by chance, both twins of a dichorionic pair have similar patterns of $\mathrm{X}$ inactivation. This is not unexpected, since the majority of females have $X$ inactivation patterns around 50:50 (see Fig. 3). In contrast, $X$ chromosome inactivation patterns are always highly similar in the blood of monochorionic twin pairs, presumably because this tissue is shared between the two members of a twin pair. Thus, the final value should represent an average of independent $\mathrm{X}$ inactivation events in the two twins. This averaging would occur by virtue of continuous mixing of their blood supplies during fetal life.

There is an alternative explanation for the similarity in $\mathrm{X}$ chromosome inactivation patterns in monochorionic twin pairs. This relates to the presumed timing of monochorionic twinning relative to $X$ chromosome inactivation. Exact knowledge of the timing of these events is not available. However, it is presumed that monochorionic twinning occurs relatively late $(>4$ days postfertilization), and recent studies in the mouse suggest that $\mathrm{X}$ chromosome inactivation may also occur in the latter part of this period (15). Thus, it is possible that in some cases monochorionic twinning occurs after $\mathrm{X}$ inactivation. If this is the case, then both twins would be expected to have highly correlated $X$ inactivation patterns, regardless of their shared placental blood supply. By this argument, dichorionic twin pairs would not be expected to have highly correlated patterns of $\mathrm{X}$ inactivation, since dichorionic twinning presumably occurs early, before $\mathrm{X}$ chromosome inactivation.

This question could be resolved by studying $\mathrm{X}$ inactivation patterns in nonhematopoietic tissues of monochorionic twin pairs. However, this experimental problem is complicated by the patchy distribution of $X$ inactivation in solid tis- 
sues. This phenomenon is well known to dermatologists who observe a patchy distribution of $\mathrm{X}$-linked phenotypes along Blaschko's lines in carrier females $(16,17)$. Because of the large size of these patches, a single biopsy of epidermis or circumscribed sample of buccal mucosa will not be likely to yield representative results for the entire tissue. It appears that the patch size in dermis and other internal organs is considerably smaller (18). However, these tissues are not readily available for sampling in human $\mathrm{MZ}$ twin pairs. There is no information on the degree of patchiness in fetal membranes or umbilical cords, which are the most obvious source for a future analysis. Since hematopoietic cells are constantly mixing, this is not an issue for the studies reported here.

One reason for embarking on this study was to investigate whether differences in $\mathrm{X}$ chromosome inactivation patterns in $\mathrm{MZ}$ twins might be related to the high discordance rates for autoimmune diseases in MZ twin pairs (19). It is unclear whether genes on the $X$ chromosome influence susceptibility to autoimmunity; however, several genes on the $X$ chromosome are involved in the regulation of the immune or inflammatory response, including the CD40 ligand (20), IL2-R (21), and tissue inhibitor of metalloproteinase (22), to name a few. Conceivably, $\mathrm{X}$ inactivation differences in twins might result in different patterns of expression of alleles at these loci. Alternatively, $X$ chromosome inactivation patterns might relate to concordance for autoimmunity by virtue of the fact that the majority of $M Z$ twins with highly similar patterns of $\mathrm{X}$ inactivation were monochorionic. As discussed previously, monochorionic twins share their fetal blood supply during gestation and thus share a common immune system. In particular, monochorionic twins would have in common the prenatal stochastic events associated with immunoglobulin and $\mathrm{T}$ cell receptor gene rearrangement (2), whereas dichorionic twin pairs would undergo these gene rearrangements independently of one another during fetal life.

We therefore searched for an association between dissimilar patterns of $\mathrm{X}$ chromosome inactivation (high standardized difference) and discordant expression of autoimmune disease. In the discordant twin pairs 6 out of 12 twin pairs had SD values $>4.0$, whereas only 4 out of 14 concordant twin pairs had such high SD values. However, this difference between the two groups of twins was not statistically significant. Thus, we were not able to establish an association between
$\mathrm{X}$ chromosome inactivation patterns and autoimmunity.

The most parsimonious interpretation of these results is that differences in relative expression of $\mathrm{X}$ linked alleles do not influence disease expression in twins. Furthermore, if $\mathrm{X}$ inactivation patterns reflect fetal-placental anatomy, it appears that twin placentation patterns also have no influence on concordance for autoimmune disease in $\mathrm{MZ}$ twins. Thus, the high discordance rate for autoimmune disease in twins appears to be due in large part to environmental or other developmental differences. However, several potential caveats to this conclusion should be kept in mind. For example, if X-linked genes are involved in disease susceptibility, only those twins that are heterozygous for the relevant alleles would be affected by dissimilar patterns of $\mathrm{X}$ chromosome utilization. In addition, the genetic background of some twins may predispose to concordance, overwhelming more minor effects of monochorionic anatomy or the modifying effects of X-linked genes. In this regard it is of interest that $\mathrm{MZ}$ twins with rheumatoid arthritis are much more likely to be concordant for disease if they are homozygous for the relevant MHC class II susceptibility genes, such as HLADR4 (23). Thus, $X$ inactivation patterns may be associated with discordance only in twins lacking these strong susceptibility genes and having an overall higher threshold for disease. The number of twins available did not permit us to directly address these possibilities. It should also be pointed out that in this study we have investigated $\mathrm{X}$ chromosome inactivation patterns only in peripheral blood, which is of mesodermal origin. However, $\mathrm{X}$ chromosome inactivation patterns may vary in tissues of different embryologic origin (15) (unpublished data). Conceivably, X inactivation patterns in these other tissues might influence the expression of disease. These considerations suggest to us that more comprehensive studies of $\mathrm{MZ}$ twin pairs may yet reveal subtle host differences between such twins, which contribute to the high discordance rates for autoimmunity.

Finally, as shown in Fig. 4C, we have occasionally observed (in 2 out of 41 twin pairs) an unusual pattern of $\mathrm{X}$ chromosome inactivation in which both members of the twin pair are extremely skewed in the same direction. Interestingly, both these twin pairs were in the RA group. However, we have also observed this in an additional set of normal twins not included in this study. It would seem unlikely for this to 
occur by chance in both members of a dichorionic twin pair, nor would averaging of $\mathrm{X}$ inactivation events in monochorionic pairs commonly result in this pattern. This pattern could occur if a highly skewed $X$ inactivation event preceeded twinning. Alternatively, some $X$ chromosomes may carry alleles that influence the likelihood of undergoing inactivation. Such alleles have been described in the mouse (24) but have not been reported in humans. Family studies of these twin pairs might reveal further evidence of this phenomenon.

\section{ACKNOWLEDGMENTS}

This work was supported by a Pilot Research Grant from the National Multiple Sclerosis Society and by generous donations to P.K.G. from Mr. and Mrs. James C. Dudley and the Guilford Fund. Support was also provided by the Fund for Medical Scientific Research (Belgium). P.K.G. is especially grateful to Drs. Jennifer Puck and Harry Ostrer for helpful discussions and advice during the early phases of this work, to Tom Mack for many informative conversations about twins, and to Daniel Kastner for critical review of the manuscript. We also wish to thank Dr. Robert Pergolizzi for technical support and advice and Francine S. Mandel for help with biostatistics.

\section{REFERENCES}

1. Cunningham TG, MacDonald PC, Gant NF. (1989) Williams Obstetrics, 18th Ed. Appleton \& Lange, Norwalk, CT, pp. 629-652.

2. Schatz DG, Oettinger MA, Schlissel MS. (1992) V (D) J recombination: Molecular biology and regulation. Annu. Rev. Immunol. 10: 359-383.

3. Gartler SM, Riggs AD. (1983) Mammalian $\mathrm{X}$-chromosome inactivation. Ann. Rev. Genet. 17: 155-190.

4. Puck J, Stewart C, Nussbaum R. (1992) Maximum likelihood analysis of $\mathrm{T}$ cell $\mathrm{X}$ chromosome inactivation patterns: Normal women versus carriers of $\mathrm{X}$ linked severe combined immunodeficiency. Am. J. Hum. Genet. 50: 742-748.

5. Allen C, Zoghbi HY, Moseley AB, Rosenblatt HM, Belmont JW. (1992) Methylation of HpaII and HhaI sites near the polymorphic CAG repeat in the human androgen-recep- tor gene correlates with $\mathrm{X}$ chromosome inactivation. Am. J. Human. Genet. 51: 12291239.

6. Philip J, Vogelius Anderson $\mathrm{CH}$, Dreyer V, Freiesleber E, Gurtler H, Hauge M, Kissmeyer-Nielsen F. (1969) Color vision deficiency in one of two presumably monozygotic twins with secondary amenorrhoea. Ann. Hum. Genet. 33: 185-195.

7. Phelan MC, Morton CC, Swenson PM, Winter PM, Nance WE. (1980) Evidence for lyonization of G-6-PD in a monozygotic twin pair. Am. J. Hum. Genet. 32: 123A.

8. Neidich JA, Nussbaum RL, Packer RJ, Emanuel BS, Puck JM. (1990) Heterogeneity of clinical severity and molecular lesions in Aicardi syndrome. J. Pediatrics 116: 911-917.

9. Richards CS, Watkins SC, Hoffman EP, Schneider NR, Milsark IW, Katz KS, Cook JD, Kunkel LM, Cortada JM. (1990) Skewed $\mathrm{X}$ inactivation in a female $\mathrm{MZ}$ twin results in Duchenne Muscular Dystrophy. Am. J. Hum. Genet. 46: 672-681.

10. Ebers GC, Bulman DE, Sadovnick AD, Paty DW, Warren S, Hader W, Murray TJ, Seland TP, Dugquette P, Grey T, Nelson R, Nicolle M, Brunet D. (1986) A population-based study of multiple sclerosis in twins. New Engl. J. Med. 315: 1638-1642.

11. Olmos P, Hern RA, Heaton DA, Millward BA, Risley D, Pyke DA, Leslie RD. (1988) The significance of the concordance rate for Type I (insulin-dependent) diabetes in identical twins. Diabetologia 31: 747-750.

12. Deapen D, Escalante A, Weinrib L, Horwitz D, Bachman B, Roy-Burman P, Walker A, Mack TM. (1992) A revised estimate of Twin concordance in systemic lupus erythematosus. Arthritis Rheumat. 35: 311-318.

13. Silman AJ, McGregor A, Thomson W, Holligan S, Carthy D, Ollier WER. (1993) Twin concordance rates for rheumatoid arthritis: Results of a nationwide study. Brit. J. Rheumatol. 32: 903-907.

14. Jeffreys AJ, Wilson V, Thein SL. (1985) Hypervariable minisatellite regions in human DNA. Nature 314: 67-73.

15. Tan S-S, Williams EA, PPL Tam. (1993) X chromosome inactivation occurs at different times in different tissues of the post-implantation mouse embryo. Nature Genet. 3: 170174.

16. Happle R. 1985. Lyonization and the lines of Blaschko. Hum. Genet. 70: 200-206.

17. Bolognia JL, Orlow S, Glick SA. (1994) Lines 
of Blaschko. J. Am. Acad. Dermatol. 31: 157192.

18. Fialkow PJ. (1976) Clonal origin of human tumors. Biochim. Biophys. Acta. 458: 283-321.

19. Gregersen PK. (1993) Discordance for autoimmunity in monozygotic twins: Are "identical" twins really identical? Arthritis Rheumat. 26: 1185-1192.

20. Aruffo A, Farrington $M$, Hollenbaugh D, Li $\mathrm{X}$, Milatovich A, Nonoyama S, Bajorath J, Grosmaire LS, Stenkamp R, Neubauer M, RL Roberts, Noelle RJ, Ledbetter A, Francke U, Ochs HD. (1993) The CD40 ligand, gp39, is defective in activated $\mathrm{T}$ cells from patients with X-linked hyper-IgM syndrome. Cell 72: 291-300.

21. Noguchi M, Yi H, Rosenblatt HM, Filipovich AH, Adelstein S, Modi WS, McBride OW, Leonard WJ. (1993) Interleukin 2 receptor $\gamma$ chain mutation in X-linked severe combined immunodeficiency in humans. Cell 73: 147157.

22. Derry JMJ, Barnard PJ. (1992) Physical linkage of the A-raf-1, properdin, synapsin I, and TIMP genes on the human and mouse $X$ chromosomes. Genomics 12: 632-663.

23. Jawaheer D, Thompson $\mathrm{W}$, MacGregor AJ, Carthy D, Davidson J, Dyer PA, Silman AJ, Ollier WER. (1994) "Homozygosity" for the HLA-DR shared epitope contributes the highest risk for rheumatoid arthritis concordance in identical twins. Arthritis Rheumat. 37: 681-686.

24. Johnson PG, Cattanach BM. (1981) Controlling elements in the mouse IV. Evidence of non-random $\mathrm{X}$ inactivation. Genet. Res. 37: 151-160. 